\title{
RSW Junctions of Advanced Automotive Sheet Steel by Using Different Electrode Pressures
}

\author{
Abdulkarim Alzahougi \\ Faculty of Technology \\ Karabuk University \\ Karabuk, Turkey \\ aalzahougi@yahoo.com
}

\author{
Muhammed Elitas \\ Faculty of Technology \\ Karabuk University \\ Karabuk, Turkey \\ melitas@karabuk.edu.tr
}

\author{
Bilge Demir \\ Faculty of Engineering \\ Karabuk University \\ Karabuk, Turkey \\ bdemir@karabuk.edu.tr
}

\begin{abstract}
The effects of different types of welding current and electrode pressure on tensile shear properties of resistance spot welding (RSW) of commercial DP600 steel have been investigated in this study. In tensile shear tests of the welded joints, tensile shear force and maximum displacement were utilized to characterize the performance of the welding process. Nugget diameter has been measured to create a clear definition of RSW physical properties. Experimental results show that tensile shear load bearing capacity increases as the electrode pressure increases. Low current value occurs at low and at high electrode pressures. During high current value, the material can exhibit superior mechanical properties. The effect of electrode pressure on tensile shear load bearing capacity increases as welding current increases.
\end{abstract}

Keywords-DP600; RSW; electrode pressure; tensile shear force; mechanical properties

\section{INTRODUCTION}

Global demand for energy saving and increasing concern for environmental pollution and global warming affect the scientific community and relevant studies are on the rise. The improvement of strength, capacity and properties of materials, most importantly metals, reduces material cross section, the reduction of part weight and the resultant decrease in fuel consumption, has made possible to reduce greenhouse gas emissions. For various functional requirements of current vehicles, advanced high strength steel is the ideal solution [1]. One of the most important and most valuable properties of advanced strength steels is the excellent strength-ductility relationship. DP and the TRIP steels have been developed for this purpose. DP steels usually have tensile strength of 600$1200 \mathrm{MPa}$ and elongation of $15-25 \%$ [2]. DP steels are absorptive and are endowed with high tensile strength, low yield strength or tensile strength ratio, perfect formability, and high tensile energy. These advantages make DP steels attractive for automotive applications [3]. RSW is the major joining technique utilized for automobile production and manufacturing. A common automotive body consists of a broad number of RSW, between 3000 and 5000 spots [4]. During RSW, broad changes in the mechanical and metallurgical properties of the weld metal and the heat affected zone (HAZ) are taking place. The investigation of these changes is important and relevant for the safety, protection and strength of the welded joints [5].

Some studies examined the mechanical properties of RSW junctions of DP steels. Authors in [6] laid emphasis on the carbon equivalence which increases the hardness of the weld zone which in turn forms a very strong correlation between chemical composition and mechanical properties. Advanced high strength steel (AHSS), reached much higher tensile strength than the conventional high strength steel (HSS). Authors in [7] studied and examined the welding process design and optimization of RSW parameters. They observed the tensile strength values which revealed weaker correlation with higher current. Authors in [8] studied the microstructure of RSW and the friction stir welded (FSW) with DP600 samples. The results of the RSW HSS showed that the high strength-weight ratio and its mechanical properties are ideal for automotive applications. However, it has been noticed that microstructure changes alongside with RSW affect mechanical properties with transformations occurring in the base metal microstructure. Authors in [9] noted that the effect of welding currents on the capacity of the welding strength lasts longer than welding time. Authors in [10] observed the effect of the weld nugget size on the overload fracture mode of the RSW samples. In [11], a discovery was found about optimal welding parameters which were selected through the utilization of Taguchi experimental design method. Authors in [12] examined, evaluated and studied the transition of the RSW DP780 steel from the interface-fracture mode to the pullouttype of the fracture mode in tension and in transverse stress loading situations. Authors in [13] investigated the effect of holding time on microstructure, hardness and mechanical properties for the welded joints with different levels of thickness. Authors in [14] investigated the effects of multistage tempering process on nugget size, microstructure, microhardness and tensile fracture behavior of the DP590 steel with RSW while utilizing finite element models. Authors in [15] investigated the welded joints of the DP980 steel sheets and the effects on stiffness properties of the pulsed current.

There are many studies on welding, however they are typically and usually about welding parameters like weld current, weld time etc. in relation with the electrode pressure or force. To the best of our knowledge there hasn't been any 
research conducted on RSW junctions of the AHSS particularly in relation to the DP600 sheet steel through the utilization of different electrode pressures. Regarding advanced automotive sheet steels, DP600 has a proper place and relevance based on its properties and low cost when compared to other AHSS. In this study, RSW process was applied to DP600 at different welding currents and electrode/weld pressures. Tensile shear tests were applied to the base material (BM) and the RSW samples at electrode pressures of 2-6bar at $5 \mathrm{kA}$ and $7 \mathrm{kA}$ welding currents. The effects of the different electrode/weld pressures and welding currents on tensile shear properties of the DP600 steel were investigated.

\section{EXPERIMENTAL PROCEDURE}

Commercial DP600 steel is available in sheet metal layers of $250 \mathrm{~mm} * 250 \mathrm{~mm} * 1 \mathrm{~mm}$. 230VAC heat input, $50 \mathrm{~Hz}$ frequency and 2500VA power capacity from the SPECTROLAB model LAVFA18A were utilized to determine the chemical composition of the DP600 steel material. Steel's chemical composition is shown in Table I while its microstructure is shown in Figure 1.

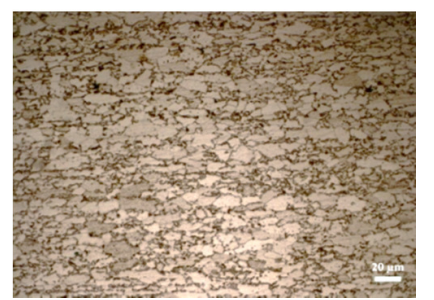

Fig. 1. Microstructure view of DP600 steel

TABLE I. CHEMICAL COMPOSITION OF DP600 STEEL (\%)

\begin{tabular}{|c|c|c|c|c|c|c|}
\hline Material & $\mathbf{C}$ & $\mathbf{S i}$ & $\mathbf{M n}$ & $\mathbf{S}$ & $\mathbf{C r}$ & $\mathbf{N i}$ \\
\hline \multirow{3}{*}{ DP600 } & 0.077 & 0.253 & 1.86 & 0.006 & 0.177 & 0.012 \\
\cline { 2 - 7 } & $\mathbf{A l}$ & $\mathbf{T i}$ & $\mathbf{V}$ & $\mathbf{S n}$ & $\mathbf{F e}$ & \\
\cline { 2 - 8 } & 0.127 & 0.002 & 0.004 & 0.006 & 97.472 & \\
\hline
\end{tabular}

The samples were designed according to EN ISO 14273 standard for the RSW operation. The RSW samples were cut to dimensions of $100 \mathrm{~mm} * 30 \mathrm{~mm} * 1 \mathrm{~mm}$ through the shearing process from the $250 \mathrm{~mm} * 250 \mathrm{~mm}$ sheets. The samples were overlapped for $35 \mathrm{~mm}$. With the consequent size of RSW, overlapped samples were $165 \mathrm{~mm}$. RSW was carried out through the utilization of two different welding currents, $5 \mathrm{kA}$ and $7 \mathrm{kA}$, and 5 different electrode pressures of 2-6bar. The AC machine for the spot welding was equipped with a device for the pneumatic control of the phase shift of the AC current. Before their joining, the surface of the test pieces was cleaned and thereafter the welded utilized conical water-cooled $\mathrm{Cu}-\mathrm{Cr}$ alloy electrodes. The diameter of the contact surface of the electrode was $8 \mathrm{~mm}$ [16]. The woodworking mould was utilized to readjust the samples during the welding, to avoid axis misalignment and to protect and readjust the sparks from spattering. Three-resistance spot welded samples were created singularly for each experiment parameter. The water-cooling system of the electrodes was kept under specific constant water control because of the excess of the heat input. RSW parameters utilized in this study are presented in Table II [17,
18]. The time unit is cycle-based (1cycle $=0.02 \mathrm{~s}$ ). The RSW process steps and a sample photograph are shown in Figures 2 and 3 respectively.

TABLE II. WELDING PARAMETERS FOR RSW PROCESSING

\begin{tabular}{|c|c|}
\hline Electrode pressure (bar) & $2-6$ \\
\hline Welding current (kA) & 5,7 \\
\hline Electrode tip diameter (mm) & 8 \\
\hline Down time (cycle) & 15 \\
\hline Squeeze time (cycle) & 35 \\
\hline Welding time (cycle) & 20 \\
\hline Hold time (cycle) & 10 \\
\hline Separation time (cycle) & 15 \\
\hline
\end{tabular}
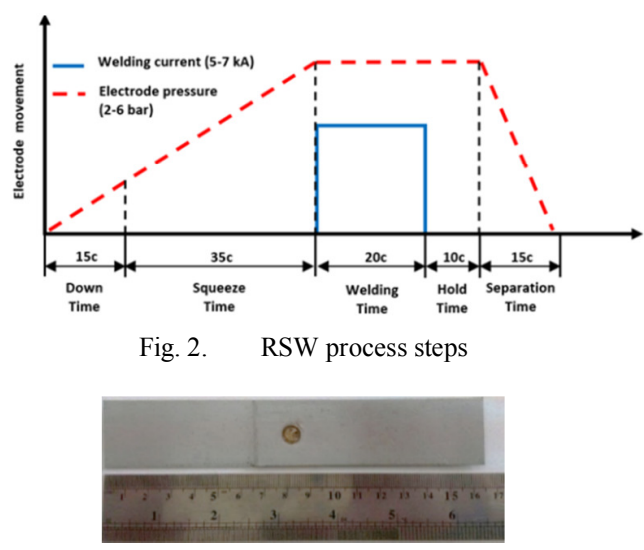

Fig. 3. RSW sample image

Tensile shear test parameters are the $5 \mathrm{kA}$ and $7 \mathrm{kA}$ welding currents, and 2 bar to 6bar electrode pressures. The samples were tested for each of the experimental parameters and the arithmetic means of these values were calculated. In addition, tensile test was applied to the base material for comparison. In addition to the tensile shear data which has been generally utilized in the literature, there is now a reference to the parts of the joining made on the nugget welding profile shown in Figure 3. In this way, shear data are also considered as stress data. RSW samples had $1 \mathrm{~mm}$ thickness, $30 \mathrm{~mm}$ width and $110 \mathrm{~mm}$ gauge length. The crosshead speed value utilized for the tensile shear test was $2 \mathrm{~mm} / \mathrm{min}$ [16].

\section{RESULTS AND DISCUSSION}

During tensile shear tests, maximum tensile shear force value which allows the fracture to occur was evaluated and examined to assess the tensile shear load bearing capacity characteristics of the joint [18]. Base material was also subjected to tensile test. The effects of electrode pressure and welding current on tensile shear load bearing capacity were studied. Authors in [17] reported that micro voids of large size were formed in the low electrode forces of the RSW process. It was observed that nugget solidifies before electrodes were moved away from the weld region. Since the weld nugget was not sufficiently suppressed at relatively lower electrode forces, shrinkage voids were formed because of the low stress during this time [17]. In addition to other approaches, and because of increased electrode progression and cramping as the electrode force increases, the significant parts of the voids are closed, and fewer shrinkage voids occur in the welded area. Any increment 
of the welding current provides a capable level of current efficiency. Hence, the effectiveness of the welding processes increases [3, 17]. Through this discovery, variations of the nugget diameter were investigated in the RSW joints which depended on the welding parameters. The strong relationship between the increment of maximum tensile shear load bearing capability and the increment of the area been subjected to upcoming stress level was caused by the nugget diameter [5]. Obtained results of the tensile shear test are presented in Tables III and IV for samples joined with $7 \mathrm{kA}$ and $5 \mathrm{kA}$ respectively.

TABLE III. TENSILE SHEAR TEST RESULTS WITH 7kA WELDING CURRENT

\begin{tabular}{|c|c|c|c|}
\hline $\begin{array}{c}\text { Electrode } \\
\text { pressure (bar) }\end{array}$ & $\begin{array}{c}\text { Nugget } \\
\text { diameter }(\mathbf{m m})\end{array}$ & $\begin{array}{c}\text { Tensile shear } \\
\text { force (kN) }\end{array}$ & $\begin{array}{c}\text { Maximum } \\
\text { displacement (mm) }\end{array}$ \\
\hline 2 & 7.49 & 13.1687 & 5.382 \\
\hline 3 & 7.62 & 13.8750 & 6.877 \\
\hline 4 & 7.89 & 13.9156 & 6.818 \\
\hline 5 & 7.22 & 13.4875 & 7.434 \\
\hline 6 & 7.06 & 12.2219 & 4.430 \\
\hline Base Material & - & $19.2125^{*}$ & 13.665 \\
\hline
\end{tabular}

*This is the ultimate tensile force for base material's condition of unwelded or before welding. Differentiating from others, it wasn't spot-welded. It had size of $100 * 30$ and it is one of the overloaded parts. It was tested in order to evaluate maximum load bearing-capacity.

TABLE IV. TENSILE SHEAR TEST RESULTS WITH 5kA WELDING CURRENT

\begin{tabular}{|c|c|c|c|}
\hline $\begin{array}{c}\text { Electrode } \\
\text { pressure (bar) }\end{array}$ & $\begin{array}{c}\text { Nugget } \\
\text { diameter (mm) }\end{array}$ & $\begin{array}{c}\text { Tensile shear } \\
\text { force }(\mathbf{k N})\end{array}$ & $\begin{array}{c}\text { Maximum } \\
\text { displacement (mm) }\end{array}$ \\
\hline 2 & 7.41 & 13.5594 & 7.979 \\
\hline 3 & 7.63 & 13.6938 & 7.968 \\
\hline 4 & 7.71 & 13.7605 & 7.136 \\
\hline 5 & 7.91 & 13.8359 & 7.953 \\
\hline 6 & 7.15 & 13.5609 & 8.097 \\
\hline
\end{tabular}

The maximum tensile shear load bearing capacity of the samples increased along with electrode pressure until 4bar. After this pressure level, it showed a high tendency to decrease. This shows that 4 bar pressure is the optimum value for $7 \mathrm{kA}$ RSW. At welding current of $5 \mathrm{kA}$, the maximum tensile shear load bearing capacity was reached at 5 bar, indicating a higher tendency to decrease afterwards (Table IV). Sensitive values were taken from the graph (Figure 4), as the event in which the melt-pressure exceeded $7 \mathrm{kA}-4 \mathrm{bar}$ and $5 \mathrm{kA}-5$ bar respectively. In that stage, electrodes undergo a much deeper level of sinking with excessive pressure and thus nugget thickness is reduced $[17,19]$. The thickness of the RSW nugget-base material had passed the lateral area, which was also falling at a time. The lateral area forms a core basis for tensile approach. The decrease in the lateral area and the decrease in the nugget thickness coexist [5]. The indentation depth ought not to be beyond $30 \%$ of the sheet thickness $[2,9]$. The electrode depth indentation experimental values were within standard levels. Nugget formation was strongly examined as dependent on the material type and welding parameters. The excessive sinking of the electrodes to the RSW samples causes an increment in the welding heat input because of the excessive increase of the indentation-contact. Excessive heat input, strong electrode contact, and electrode retention could disrupt the nugget geometry and weld profile. Moreover, the pressure can cause cracks on the nugget surface and lateral surface areas. In addition, excessive heat input causes grain growth in the HAZ and weld metal and causes the strength to decrease [3, 5]. Studies on advanced strength steels show a strong relationship between nugget size and tensile shear strength [3, 20]. The mean diameter of the nugget had been measured as been up to approximately $7 \mathrm{~mm}$ in [21-24] and it can be used for DP600 steel [4]. These results can be explained by $5 \sqrt{t}$ rule (t: material thickness), which was recommended to be the most appropriate rule according to Japanese [25] and German [26] standards. After examination of the results in Tables III and IV, it was seen that the strength of the DP600 steel increased in direct proportion to the nugget diameter until an optimum value and it decreased thereafter [18]. Maximum tensile shear force values obtained at these different welding currents depended on the electrode pressure (Figure 4). The 7kA-4bar values of the RSW were near to ideal. The maximum tensile shear load bearing capacity value occurred at 5 bar electrode pressure in $5 \mathrm{kA}$ samples. The effect of the electrode pressure on the tensile shear force is greater in the $7 \mathrm{kA}$ samples. The graph of the $5 \mathrm{kA}$ samples is almost horizontal. This shows that the effect and the sensitivity of the electrode pressure were lower at lower current values. Because of this, it was asserted that as the current increases, the effect of the pressure increases. As the electrode pressure increases, the welding current will have the potential to decrease.

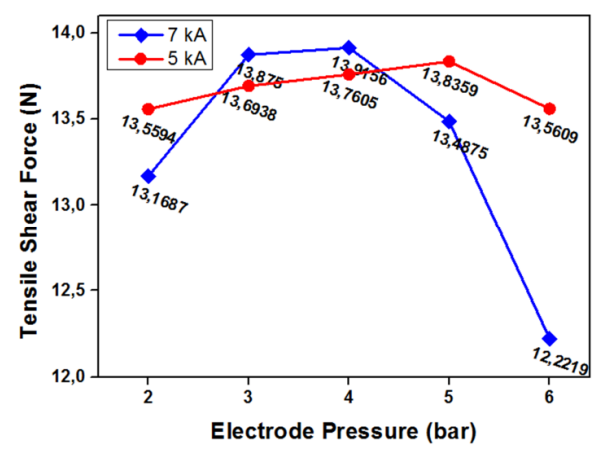

Fig. 4. Maximum tensile shear force values obtained

The highest reported tensile shear force values were from $12.5 \mathrm{kN}$ to $16.67 \mathrm{kN}$ [17], $13.69 \mathrm{kN}$ [21], $11.67 \mathrm{kN}$ [18], 3.125$9.75 \mathrm{kN}$ [2], and $10-14.7 \mathrm{kN}[27]$. The greatest value of the tensile shear load bearing capacity was, reported in [17] and the lowest in [2]. Some of the differences observed between maximum tensile shear force values can be attributed to differences in the chemical composition of the steels used, RSW parameters, and sheet thickness. The tensile shear load bearing capacity obtained in our study resulted in a category that could be classified as been close to high values.

\section{CONCLUSIONS}

RSW process was applied to the commercial automotive sheet steel DP600 at different welding currents and electrode/weld pressures. These tensile shear tests were applied to the base material and to the RSW samples at electrode pressures of $2 \mathrm{bar}$ to $6 \mathrm{bar}$ at $5 \mathrm{kA}$ and $7 \mathrm{kA}$ welding currents. The effects on the tensile shear properties of the DP600 steel were studied and the following results were obtained:

- At lower current values, effect and sensitivity of the electrode pressure were observed to be less. As the current 
increased, the effect of the pressure increased. As the electrode pressure increased, the welding current could also reduce.

- Welding parameters and nugget diameter are important factors that determine the load-bearing capacity of the overloaded RSW junction samples.

- The welding current efficiency had increased up to 4 bar at $7 \mathrm{kA}$ welding current and up to 5 bar at $5 \mathrm{kA}$ welding current. As the welding current increased, heat input, nugget diameter, tensile shear force value, and maximum tensile shear load bearing capacity increased.

- The tensile shear load bearing capacity was directly proportional to the nugget diameter.

- Tensile strength of the base material decreased after RSW.

\section{ACKNOWLEDGMENT}

This work was supported by the Scientific Research Projects Coordination Unit of Karabuk University (Karabuk, Turkey). Project Number: KBÜBAP-17-KP-463.

\section{REFERENCES}

[1] M. A. Erden, "The effect of the sintering temperature and addition of niobium and vanadium on the microstructure and mechanical properties of micro alloyed PM Steels", Metals, Vol. 7, No. 9, pp. 1-16, 2017

[2] S. M. Mule, S. U. Ghunage, B. B. Ahuja, "Process characterization of resistance spot welding of dual phase stainless (DP600) steel", 6th International \& 27th All India Manufacturing Technology, Design and Research Conference, Maharashtra, India, December 16-18, 2016

[3] M. Elitas, B. Demir, O. Yazici, "The effects of the electrode pressure on tensile strength and fracture modes of the RSW junctions of DP600 sheet steel", 2nd International Conference on Material Science and Technology in Cappadocia, Nevsehir, Turkey, October 11-13, 2017

[4] H. Fujimoto, H. Ueda, R. Ueji, H. Fujii, "Improvement of fatigue properties of resistance spot welded joints in high strength steel sheets by shot blast processing”, ISIJ International, Vol. 56, No. 7, pp. 12761284, 2016

[5] F. Hayat, B. Demir, M. Acarer, S. Aslanlar, "Effect of weld time and weld current on the mechanical properties of resistance spot welded IF (DIN EN 10130-1999) steel”, Kovove Materialy, Vol. 47, No. 1, pp. 1117,2009

[6] M. L. Kuntz, E. Biro, Y. Zhou, "Microstructure and mechanical properties of resistance spot welded advanced high strength steels", Materials Transactions, Vol. 49, No. 7, pp. 1629-1637, 2008

[7] M. Pradeep, N. S. Mahesh, R. Hussain, "Process parameter optimization in resistance spot welding of dissimilar thickness materials", International Journal of Mechanical, Aerospace, Industrial and Mechatronics Engineering, Vol. 8, No. 1, pp. 80-83, 2014

[8] M. I. Khan, M. L. Kuntz, P. Su, A. Gerlich, T. North, Y. Zhou, "Resistance spot welding (RSW) and friction stir welding (FSW) of DP600: a comparative study", Science and Technology of Welding and Joining, Vol. 12, No. 2, pp. 175-181, 2007

[9] X. Q. Zhang, G. L. Chen, Y. S. Zhang, "Characteristics of electrode wear in resistance spot welding dual-phase steels", Materials \& Design, Vol. 29, No. 1, pp. 279-283, 2008

[10] M. Pouranvari, H. R. Asgari, S. M. Mosavizadch, P. H. Marashi, M. Goodarzi, "Effect of weld nugget size on overload failure mode of resistance spot welds", Science and Technology of Welding and Joining, Vol. 12, No. 3, pp. 217-225, 2007

[11] V. K. Prashanthkumar, N. Venkataram, N. S. Mahesh, Kumarswami, "Process parameter selection for resistance spot welding through thermal analysis of $2 \mathrm{~mm}$ CRCA sheets", Procedia Materials Science, Vol. 5, pp. $369-378,2014$
[12] M. Pouranvari, S. P. H. Marashi, H. L. Jaber, "DP780 dual-phase steel spot welds: critical fusion-zone size ensuring the pull-out failure mode", Materials and Technology, Vol. 49, No. 4, pp. 579-585, 2015

[13] H. Long, Y. Hu, X. Jin, J. Shao, H. Zhu, "Effect of holding time on microstructure and mechanical properties of resistance spot welds between low carbon steel and advanced high strength steel", Computational Materials Science, Vol. 117, pp. 556-563, 2016

[14] B. Wang, L. Hua, X. Wang, J. Li, "Effects of electrode tip morphology on resistance spot welding quality of DP590 dual phase steel", The International Journal of Advanced Manufacturing Technology, Vol. 83, No. 9-12, pp. 1917-1926, 2016

[15] C. Sawanishi, T. Ogura, K. Taniguchi, R. Ikeda, K. Oi, K. Yasuda, A. Hirose, "Mechanical properties and microstructures of resistance spot welded DP980 steel joints using pulsed current pattern", Science and Technology of Welding and Joining, Vol. 19, No. 1, pp. 52-59, 2014

[16] F. Hayat, I. Sevim, "The effect of welding parameters on fracture toughness of resistance spot-welded galvanized DP600 automotive steel sheets", The International Journal of Advanced Manufacturing Technology, Vol. 58, No. 9-12, pp. 1043-1050, 2012

[17] C. Ma, D. L. Chen, S. D. Bhole, G. Boudreau, A. Lee, E. Biro, "Microstructure and fracture characteristics of spot-welded DP600 steel", Materials Science and Engineering: A, Vol. 485, No. 1-2, pp. 334-346, 2008

[18] M. I. Khan, M. L. Kuntz, E. Biro, Y. Zhou, "Microstructure and mechanical properties of resistance spot welded advanced high strength steels", Materials Transactions, Vol. 49, No. 7, pp.1629-1637, 2008

[19] T. K. Pal, K. Bhowmick, "Resistance spot welding characteristics and high cycle fatigue behaviour of DP780 steel sheet", Journal of Materials Engineering and Performance, Vol. 21, No. 2, pp. 280-285, 2012

[20] Y. Kaya, N. Kahraman, "The effects of electrode force, welding current and welding time on the resistance spot weldability of pure titanium", The International Journal of Advanced Manufacturing Technology, Vol. 60, No. 1-4, pp. 127-134, 2012

[21] X. Long, S. K. Khanna, "Fatigue properties and failure characterization of spot welded high strength steel sheet", International Journal of Fatigue, Vol. 29, No. 5, pp. 879-886, 2007

[22] H. Zhang, A. Wei, X. Qiu, J. Chen, "Microstructure and mechanical properties of resistance spot welded dissimilar thickness DP780/DP600 dual-phase steel joints", Materials \& Design, Vol. 54, pp. 443-449, 2014

[23] S. Daneshpour, M. Kocak, S. Riekehr, C. H. J. Gerritsen, "Mechanical characterization and fatigue performance of laser and resistance spot welds", Welding in the World, Vol. 53, No. 9-10, pp. 221-228, 2009

[24] M. Elitas, B. Demir, "The effects of the welding parameters on tensile properties of RSW junctions of DP1000 sheet steel", Engineering, Technology \& Applied Science Research, Vol. 8, No. 4, pp. 3116-3120, 2018

[25] JIS Z3140. Method of inspection for spot welds, Japanese Industrial Standard 1989

[26] DVS 2923. Resistance Spot Welding, German Standard

[27] D. Zhao, Y. Wang, D. Liang, P. Zhang, "An investigation into weld defects of spot-welded dual-phase steel", The International Journal of Advanced Manufacturing Technology, Vol. 92, No. 5-8, pp. 3043-3050, 2017 